Revista del Centro de Investigación de la Universidad La Salle

Vol. 12, No. 46, julio-diciembre, 2016: 11-38

http://ojs.dpi.ulsa.mx/index.php/rci/

\title{
La ipseidad: un intento de reformulación
}

The ipsiety: a reformulation attempt

\author{
Claude ROMANO ${ }^{1}$ \\ Université de Paris-Sorbonne (Francia)/Australian Catholic \\ University (Australia)
}

Fecha de recepción: 24 Febrero de 2017

Fecha de aceptación: 24 Febrero de 2017

Disponible en línea: 23 marzo 2017

\footnotetext{
${ }^{1}$ Traducción de Ramsés Leonardo Sánchez Soberano (el traductor agradece a Lisset Ximena Latisnere Juárez por su ayuda en la transcripción del documento final).

E-mail: $\underline{\text { ramses.sanchez@ulsa.mx }}$
}

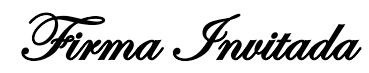

\section{(c) (i) (2) (-)}

Revista del Centro de Investigación de la Universidad La Salle por Dirección de Posgrado e Investigación. Universidad La Salle Ciudad de México se distribuye bajo una Licencia Creative Commons Atribución-NoComercial-CompartirIgual 4.0 Internacional. 


\section{Resumen:}

En mis dos obras consagradas al problema del acontecimiento siempre he formulado mi pensar en los términos de un pensamiento de la ipseidad y no del yo ( $m o i)$. Hoy son numerosos los autores que emplean estos dos conceptos como cuasisinónimos. Sin embargo, pienso que ambos conceptos responden a un tipo diferente de preguntas y que deben ser distinguidos. Este es el punto que quisiera aclarar en las reflexiones siguientes retomando al primer autor que ha hecho un uso peculiar de un concepto que en francés se traduce usualmente por «ipseidad», a saber, el concepto heideggeriano de Selbstheit. Por tanto, la siguiente exposición será una tentativa de explicación del concepto de ipseidad partiendo de Heidegger, y una defensa en favor de este concepto, como una alternativa a aquel -mucho más problemático a mis ojos- de yo (moi); una alternativa al camino de las egologías que han triunfado en la filosofía desde Descartes hasta Husserl.

Palabras Claves: Ipseidad, yo, Dasein. 


\section{Abstract:}

In my two works dedicated to the problem of the event, I have always formulated my thinking in terms of the ipseity as a thought and not as a thinking to the self (moi). Today, there are many authors who use these two concepts as quasisynonyms. However, I think that both concepts respond to a different type of questions and that they should be distinguished. This is the point I would like to make clear in the following reflections, referring to the first author who has made a peculiar use of a concept which in French is usually translated by "ipseity", namely, the Heideggerian concept of Selbstheit. Therefore, the following exposition will be both an attempt to explain the concept of ipseity from Heidegger and a defense in favor of this concept as an alternative to that - much more problematic in my eyes - of I (moi), an alternative to the way of the egologies that have triumphed in philosophy from Descartes to Husserl.

Keywords: Ipseity, I, Dasein. 


\section{Introducción}

En relación con el modo en que el concepto de ipseidad ha sido abordado en $E l$ acontecimiento y el mundo y El acontecimiento y el tiempo, quiero tomar algunas distancias dejando de lado un aspecto del análisis que me interesaría privilegiar: la temática de las relaciones entre la ipseidad y el acontecimiento. Quiero ampliar mi propósito analizando la cuestión de la ipseidad de manera más formal y más neutra en concomitancia con la perspectiva que tenía en aquellas obras. No volveré a las relaciones que se pudieron establecer entre la ipseidad y el cambio sino hasta el final de mi trabajo.

Comenzaré examinando los rasgos por los que la ipseidad, tal como ha sido tematizada por Heidegger (dejando de lado, por falta de tiempo, la tematización de este concepto por Paul Ricoeur en Sí mismo como otro), se distingue de los conceptos de yo (moi) y de sí (soi) (del ego de Descartes, del self de Locke); inmediatamente después examinaré las dificultades que provoca el concepto heideggeriano, especialmente desde el punto de vista lógico, pero también desde la óptica de una aproximación «gramatical» tal como la que ha privilegiado la filosofía Wittgenstein; y al final, intentaré identificar los contornos de un concepto de ipseidad muy diferente al de Heidegger pero que, al menos, me parece dar crédito a algunas de sus intuiciones fundamentales, escapando al género de dificultades que he señalado anteriormente.

\section{La ipseidad heideggeriana}

El concepto heideggeriano de Selbstheit que, en principio, preferiría no traducir, no puede comprenderse sino en contraste con la terminología de las egologías y sus conceptos centrales, el «yo» (moi) o el yo (je), yo (Ich). Sobre este punto, Sein und Zeit es formal: es una tentativa para responder a la pregunta «¿Quién?»-¿quién el Dasein?-, ella partiría de un yo dado previamente a sí mismo, que no podría sino revelarse deficiente desde el punto de vista fenomenológico: «la interpretación positiva del Dasein que ha sido dada hasta aquí prohíbe partir de la donación formal del yo para aportar una respuesta fenomenalmente 
satisfactoria a la cuestión del ¿quién?»². O, de un modo aún más explícito: «una de sus primeras tareas [de la analítica existencial] será mostrar que la posición inicial de un yo o de un sujeto dado de inmediato necesita radicalmente de la realidad fenomenal del Dasein» ${ }^{3}$. Lo que prohíbe una aproximación egológica para alcanzar una descripción adecuada del fenómeno existencial de la Selbstheit es que, precisa Heidegger, cualquiera que sea la energía con la cual ella se defiende de toda «substancialización del alma», ella no ha prestado, al menos de antemano a este yo, el carácter ontológico de la Vorhandenheit, del sersubsistente $^{4}$. Y, por supuesto, Heidegger piensa aquí todas las tentativas recurrentes que, a partir de Kant, intentan conservar el yo o un yo, pero tomando sus distancias en relación con el sustancialismo de Descartes. Tales tentativas, con Kant, Fichte o aún con Husserl, se mueven en un círculo vicioso, pues pensando este yo a la luz del concepto de subjectum, es decir, haciendo de hupokeimenon, ellas no hacen sino ratificar el marco ontológico tradicional, aquel de una ontología de la subsistencia. También, la interpretación del fenómeno de la Selbstheit deberá mantenerse muy lejos de toda aprehensión de este fenómeno como una realidad subsistente, e incluso como una realidad sin más; ella deberá desplegarse en el marco de lo que Gérard Granel ha caracterizado con justeza como «un pensamiento resueltamente no-real, que no ha aparecido todavía en ninguna parte de Occidente» ${ }^{5}$, en el cual prima la descripción de esquemas de movimiento (sich vorwegs, voraus, um zu, etcétera); de procesos, de comportamientos (Verhaltungen), de maneras de ser (Seinsweisen), es decir, de todo lo que Heidegger llama los «existenciales» unidos unos con otros por relaciones estructurales.

Uno de los signos más tangibles de esta tendencia resueltamente anti-real del pensamiento heideggeriano, y una de las maneras en las que se desmarca más abiertamente de la estrategia de las egologías tradicionales, es que, mientras que aquellas podían introducirse en un solo concepto -el yo (moi)- para pensar lo que se llama, desde Kant, «la subjetividad», aquél

\footnotetext{
${ }^{2}$ Cf., Heidegger, Sein und Zeit, op. cit., § 25, p. 116; trad. cit, p. 101.

${ }^{3}$ Sein und Zeit, op. cit., p. 46; trad. cit, p. 56.

${ }^{4}$ Ibid.

${ }^{5}$ G. Granel, «Ipse Dasein» en Etudes, París, Galilée, 1995, p. 30.
} 
debe, por el contrario, recurrir a una compleja red conceptual constituida, al menos, de tres nociones centrales: Jemeinigkeit, Selbstheit, Man-selbst. La primera, la Jemeinigkeit -es decir, el ser-en-cada-caso-mío o, como traduce Martineau, la miidad (mienneté) - designa una característica formal de todo Dasein, característica neutra a los ojos de la distinción de sus dos maneras de ser, auténtica o inauténtica. La Jemeinigkeit-que corresponde grosso modo a lo que Heidegger llamaría en sus cursos de principios de los años 20 el Sich-haben, que hace que toda vida se posea a sí misma-designa por ello también el hecho que todo Dasein existe «en vía de sí mismo», a pesar de sí (umwillen seiner)»; en otros términos, el hecho que su ser le incumba como una tarea a realizar o, según la fórmula consagrada, el hecho que el Dasein es el ente por el cual su ser mismo está en juego, el ente por el cual le va en su ser este ser. De cualquier manera, aquí tenemos el caso de una ontologización de la oïkeiôsis estoica: el Dasein es el ente que se preocupa fundamentalmente por sí y por su propia existencia, el ente que es en su ser preocupado de este ser $^{6}$. Sin embargo, hay al menos dos maneras en las que puede desplegarse concretamente esta preocupación, esta no-indiferencia de su ser por el ente ejemplar, esta no-indiferencia de su ser que pertenece a este ser mismo.

La primera consiste para el Dasein en tomar en cuenta este ser que le incumbe y en ejercitarse él mismo propia y personalmente en la difícil tarea de decidir por este ser; la segunda consiste, al contrario, en rechazar esta elección sobre los otros, es decir, en realidad, sobre todos y nadie, sobre lo que Heidegger va a llamar «el anonimato del Uno» ${ }^{7}$. De ahí los otros dos conceptos indispensables para pensar el fenómeno existencial del «sí-mismo», y que corresponden respectivamente a la modalización propia (eigentliche) e impropia (uneigentliche), auténtica e inauténtica, de la miidad (miennetè). Comencemos por el modo inauténtico, es decir, por esa modalidad de existencia en la cual el Dasein no es él mismo, sino que está perdido en el Uno: «el Sí-mismo (das Selbst) del Dasein cotidiano es el Uno mismo (das Man-selbst), que nosotros distinguimos del Sí-mismo auténtico, es decir,

\footnotetext{
${ }^{6}$ El mismo Heidegger revela el resto del trasfondo estoico de su noción de preocupación en los Prolegomena zur Geschichte des Zeitbegriffs, GA 20, pp. 419-420, refiriéndose a la carta 90 de Séneca.

${ }^{7}$ «Los dos modos de ser de la autenticidad y la inautenticidad - una y otra expresión sería elegidas terminológicamente y en el sentido estricto del término- fundándose en el hecho que el Dasein es en general determinado por la miidad» (Sein und Zeit, pp. 42-43; vers. franc., p, 54).
} 
propiamente captado. En tanto que Uno-mismo, cada Dasein está disperso en el Se, y él debe comenzar por reencontrarse» ${ }^{8}$. No podemos entrar aquí en todas las dificultades que provocan estas afirmaciones, pero revelemos de pasada al menos dos: 1) El «Uno-mismo» es un término muy curioso, ya que no se contenta con sustantivar «Man», «uno»; él le añade la palabra «sí mismo», selbst, formando así un oxímoron que designa la pérdida de sí, una existencia que se había hundido en el anonimato donde el Dasein se identifica con los otros o, más bien, no se distingue en absoluto y, en consecuencia, el contra-fenómeno de la Selbstheit. 2) Para describir el modo de ser que contrasta con el Uno, Heidegger recurre a la expresión das Selbst, que Martineau traduce oportunamente no por «el sí», sino por «el sí mismo», queriendo probablemente indicar con ello que aquí nosotros no tenemos ninguna cuestión o especie de cosa o de entidad etérea o impalpable como se da por supuesto, sino únicamente un modo de existencia. Este punto es absolutamente decisivo y, sin embargo, es bastante desconocido, o en todo caso, descuidado por los comentadores ${ }^{9}$. Él resurge de la definición dada por Heidegger del tercer concepto, aquel de la Selbstheit. La Selbstheit designa, en efecto, uno de los modos según el cual el Dasein puede existir el carácter de miidad de su ser, a saber, aquel donde se relaciona prácticamente con este ser para hacerse cargo de él y asumirlo y, así, también para decidir:

Y el Dasein nuevamente, es cada vez mío en este o aquel modo determinado de ser. Siempre está ya decidido en qué modo el Dasein es a cada vez mío. El ente por el cual en su ser le va este ser mismo se relaciona con su ser como con su posibilidad más propia [...] Y es porque el Dasein es cada vez esencialmente su posibilidad que este ente puede «elegirse» a sí mismo en su ser, ganarse, o bien perderse, o no ganarse jamás, o ganarse solamente «en apariencia». ${ }^{10}$

\footnotetext{
${ }^{8}$ Sein und Zeit, op. cit., p. 129; ver. franc., p. 109.

${ }^{9}$ Para una relación precisa de las interpretaciones sobre este punto, puede remitirse a nuestro artículo, por aparecer: «El enigma del "Selbst" en la ontología fundamental heideggeriana».

${ }^{10}$ Heidegger, Sein und Zeit, op. cit., § 9, p. 42; ver. franc., p. 54.
} 
La Selbstheit no es en absoluto una especie de realidad; ella no señala ni hacia un ente ni hacia una característica de este ente; ella designa una manera de ser, una manera de existir, una manera para el Dasein de relacionarse prácticamente con su ser para asumirlo y responderle:

La ipseidad del Dasein ha sido formalmente determinada como una especie de existir (eine Weise zu existieren), y no, en consecuencia, como un ente presentesubsistente (nicht als ein vorhandenes Seiendes). El quién del Dasein, la mayor parte del tiempo, yo no soy yo mismo, es el Uno-mismo que es. El ser-Sí-mismo auténtico se determina como una modificación existencial del Uno que conviene delimitar existencialmente. ${ }^{11}$

Lo que ya había anticipado el $\S 27$ :

El ser-Sí-mismo auténtico no reposa sobre un estado de excepción del sujeto liberado del Uno, sino que él es una modificación existencial del Uno como existencial esencial. ${ }^{12}$

La expresión «ser sí-mismo auténtico» (das eigentliche Selbstsein) es, por cierto, un pleonasmo, ya que el tipo de existencia en la cual el Dasein «es él mismo» es también aquel en el cual él existe sobre el modo propio o auténtico, mientras que la pérdida en el Uno (la inautenticidad) significa un «no-ser-sí-mismo»: «El Dasein, en primer lugar y a menudo, no es él mismo» ${ }^{13}$. En suma, «el Dasein se comprende él mismo a partir de su existencia, de una posibilidad de él mismo de ser él mismo o de no ser él mismo (er selbst oder nicht er selbst $z u$ sein)» ${ }^{14}$. No ser sí-mismo no quiere decir evidentemente aquí no ser idéntico a sí -el

\footnotetext{
${ }^{11}$ Ibíd., § 54, p. 284; Trad. franc., p. 195.

12 Ibíd., p. 149; trad. franc., p. 110.

${ }^{13}$ Ibíd., p. 116; trad. franc., p. 101.

${ }^{14}$ Ibíd., § 4, p. 12; trad. franc., p. 33.
} 
Dasein no carece de un principio de identidad ${ }^{15}$. La significación de esta expresión es aclarada en el §27 de Sein und Zeit: «Desde el comienzo, "yo" no "soy” en el sentido del Símismo propio, sino que yo soy los otros según la índole del Uno» ${ }^{16}$.

Hace falta entonces regresar a la cuestión de saber cómo traducir Selbstheit al francés. La traducción que se ha hecho corriente por «ipseidad» presenta a la vez una fuerza y una debilidad. La debilidad es que «ipseidad» parece enviar a ipseitas, es decir, a una expresión del latín escolástico que es muy cercana a hacer sinonimia con individualitas. $\mathrm{O}$, si la Selbstheit constituye una manera de ser del Dasein, ella no puede equivaler a su individualidad. La fuerza de esta traducción aparece si regresamos a la significación etimológica de la palabra «ipseidad», y así al ipse latino. Este término, en efecto, es lo que los lingüistas llaman un «intensivo que se emplea con una idea de oposición latente». Él significa: «él en oposición a otro considerado explícitamente o no» ${ }^{17}$. Así, decir Caesar ipse, es hablar de César mismo en oposición a uno de sus emisarios o a alguien que pretendiera hacerse pasar por él. $\mathrm{O}$ es exactamente este sentido que preside al empleo heideggeriano de Selbstheit: el Dasein que existe sobre el modo de la ipseidad es aquel que decide «él-mismo», es decir, propiamente, en persona, de esta «carga» o de este «peso» $(\text { Last })^{18}$ que es su ser para cada Dasein, en contraste con aquel que se vacía de este peso sobre el Uno, que delega su elección al Uno y, haciendo esto, zozobra en la irresolución. De hecho, para describir convenientemente lo que Heidegger entiende por «ipseidad», haría falta en realidad recorrer el conjunto de los existenciales concernidos: la angustia que coloca al Dasein frente a su Geworfenheit, frente a su ser-arrojado en el mundo en su inquietante extranjeridad (Umheimlichkeit) y su total ausencia de razón; el ser-para-la-muerte (Sein-zu-dem-Tode) que da conciencia al Dasein de su propia finitud; la resolución (Entschlossenheit), es decir, la

\footnotetext{
${ }^{15}$ Como toda filosofía consecuente, Heidegger admite la validez de este principio para todo ente (comprendido ahí el Dasein): «toda cosa es idéntica a ella misma» (Heidegger, GA 24, p. 242; trad. franc., Problèmes fondamentaux de la phénoménologie, p. 210).

${ }_{16}^{16}$ Sein und Zeit, op. cit., § 27, p. 129; trad. franc., p. 109.

${ }_{17}$ Alfred Ernout et François Thomas, Syntaxe latine, Paris, Klincksieck, 2002, p. 189.

${ }^{18}$ Sein und Zeit, op. cit., §29, p. 134.
} 
«re-captación del elegir», o aún el «elegir del elegir (Wählen der Wahl)» ${ }^{19}$ al encuentro del no-elegir y de la irresolución del Uno, etcétera. No es necesario para nuestro propósito entrar en toda esta descripción. Por el momento, sería suficiente indicar que esta traducción por «ipseidad» no se justifica sino hasta mucho tiempo después, que no tomemos por ipseidad, de nuevo, por la descripción de una especie de entidad, tan sutil como se quiera, y que podría desde ahora ser puesta sobre el mismo plano que el yo de las egologías. «Selbstheit» en su empleo por Heidegger es en realidad más próximo a «Selbstsein» -otro término que se le reconoce con él- que el «yo Mismo», el sí (soi). En los dos casos, nos hemos ocupado de un ser-sí-mismo, es decir, de una índole de existir y de ninguna manera de una especie de ente -y tampoco del Dasein. Si es verdad entonces que Heidegger emplea en numerosas ocasiones «das Selbst» en Sein und Zeit, las expresiones más precisas y rigurosas de lo que quiere decir -y sin duda las únicas que poseen un estatus plenamente existencial- son aquellas de Selbstheit y de Selbstsein: el ser-sí o el hecho de ser sí, la existencia como (ente) sí-misma; casi podríamos arriesgarnos: la síi-dad (soi-ité). Aquí nos hemos ocupado únicamente de una manera de ser, una manera de relacionarse consigo mismo y con su propia existencia, una manera de existir esta existencia -en lo propio (ipse) y no por procuración.

Recapitularé un tanto esquemáticamente las características de esta ipseidad tal como la concibe Heidegger de la manera siguiente:

1. La ipseidad tiene su fundamento en la miidad, es decir, en la preocupación específica que todo Dasein posee en relación consigo mismo y con su propia existencia. La ipseidad es una forma que puede revestir esta preocupación, la forma propia o auténtica, en contraste con el Man-selbst, su forma inauténtica.

2. La ipseidad procura una respuesta ontológicamente adecuada a la cuestión «¿Quién?» («¿Quién es el Dasein?»), cuestión que Heidegger pone en contraste con la cuestión «¿Qué?», aplicándose al ente vorhanden o zuhanden, subsistente o empleable.

\footnotetext{
${ }^{19}$ Ibíd., p. 268; trad. franc., p. 195.
} 
3. La ipseidad pone en juego una forma de constancia específica que no es ni la permanencia de una sustancia, ni una continuidad psicológica sobre el modelo de aquel que constituye el self lockeano; esta constancia (Ständigkeit) parece más bien una fidelidad a sí-mismo y, a este título, ella es pensada como una auto-constancia (Selbst-ständigkeit, que falta evitar traducir por «mantenimiento de sí»), contrastando con la dispersión y la inestabilidad innata

del Uno. La ipseidad es formalmente idéntica a la resolución: «La resolución constituye la fidelidad de la exigencia hacia el Sí-mismo propio» ${ }^{20}$.

4. La ipseidad no concierne a la identidad de sí del Dasein, es decir, la identidad en su sentido «ontológico-formal», la identidad numérica a través del tiempo, sino a una identidad en un sentido distinto que solo se aplica al Dasein y únicamente a él: es lo que indica muy elípticamente un pasaje de Sein und Zeit ${ }^{21}$ y, con más claridad, un pasaje de los Problemas fundamentales de la fenomenología:

El Dasein no es simplemente, como todo ente en general, idéntico a sí mismo en el sentido ontológico-formal donde cada cosa es idéntica a ella misma; el Dasein no es más simplemente conciencia de esta identidad (Selbigkeit), a diferencia de las cosas de la naturaleza, pero el Dasein comporta una identidad a sí-mismo específica (eine eigentümliche Selbigkeit): la ipseidad. Su modo de ser es tal que en un sentido, él se pertenece propiamente, él se posee a sí mismo y por esta razón puede perderse. $^{22}$

\footnotetext{
${ }^{20}$ Ibíd., p. 391; trad. franc., p. 268.

${ }^{21}$ Ibíd., p. 130: (Die Selbigkeit des eigentlich existierenden Selbst ist aber dann ontologisch durch eine Kluft getrennt von der Identität des in der Erlebnismannigfaltigkeit sicg durchhaltenden Ich». Según la traducción de Martineau: «Lo que vuelve a decir también que la mismidad propia al Sí-mismo existente auténticamente está separada ontológicamente por un abismo de la identidad del Yo tal como él se mantiene en la multiplicidad de las vivencias» (loc. cit., p. 110).

${ }^{22}$ Sein und Zeit, op. cit., p. 308.
} 
5. La ipseidad, la existencia propia o en persona, es el lugar de una forma de autotransparencia (Durchsichtigkeit) del Dasein y, por tanto, de la verdad. La resolución es así cualificada por Sein und Zeit como «verdad de la existencia» ${ }^{23}$. Ella no es únicamente la «verdad originaria» del Dasein, que Heidegger en el $\S 44$ (b) identifica con su apertura (Erschlossenheit) al ente en su conjunto, sino «la verdad más originaria, en tanto que auténtica del Dasein» ${ }^{24}$.

\section{Perplejidades «wittgensteinianas»}

Pudimos interrogarnos para saber si esta noción de ipseidad no es una noción típicamente «metafísica» en el sentido que Wittgenstein confiere a este término - es decir, no solamente una noción técnica (que lo es sin duda alguna), sino una noción cuya invención reposa al menos en parte sobre un desconocimiento de la gramática de nuestra lengua ordinaria, y que no puede en consecuencia ser esclarecida sino por el retorno «del uso metafísico al uso cotidiano», para retomar la fórmula consagrada a las Investigaciones filosóficas ${ }^{25}$. En un artículo titulado «El problema de la individualidad humana» ${ }^{26}$, Vincent Descombes ha llamado la atención sobre muchas dificultades. Una de ellas reside en la afirmación según la cual la ipseidad constituiría una forma de identidad sui generis propia al Dasein y solo a él y que diferiría de la identidad en su sentido «ontológico-formal», es decir, valiendo para todo ente cualquiera. Descombes observa con justa razón que la cuestión «¿Quién?» entendida en su sentido ordinario apunta a identificar a alguien $-\mathrm{y}$ la respuesta pertinente consiste aquí típicamente en declinar su identidad o en levantar la mano para hacerse conocer-, mientras que la cuestión «¿Quién?» en el sentido en el que Heidegger querría promover no puede tener por objetivo identificar el Dasein. Como él escribe, «la otra cuestión “¿Quién?” que Heidegger propone a propósito del hombre [¿del Dasein?] cotidiano no apunta únicamente a identificarlo, ella apunta a cualificar su relación práctica consigo mismo» ${ }^{27}$. Podemos, en

\footnotetext{
${ }^{23}$ Ídem.

${ }^{24}$ Ibíd., p. 297; trad. franc., p. 212.

${ }^{25}$ Ver por ejemplo Wittgenstein, Investigaciones filosóficas, op. cit., I, § 116.

${ }^{26}$ Aparecido inicialmente en Philosophie, 106 (2010), pp. 38-56 y retomado en V. Descombes, Le parler de soi, Paris, Gallimard, 2014, pp. 144-181.

${ }^{27}$ Le parler de soi, op. cit., p. 157.
} 
consecuencia, dudar que se haya ocupado aquí de un segundo sentido, distinto, de la identidad. La expresión «Es posible que no sea yo», entendida en el sentido de la ipseidad, no significa evidentemente que yo podría ser otro, sino, como lo hace notar Descombes, que es posible que sea yo mismo «de otro modo que en el modo de la apropiación» ${ }^{28} \mathrm{o}$ de la existencia auténtica. En efecto, en las expresiones tales como «Yo no soy yo-mismo», «Yo me convierte en mí mismo», etcétera, «yo mismo» no tiene la función de un pronombre, quien, de hecho, llamaría una identificación, pero sí aquella de un atributo que forma con el verbo una unidad semántica indisoluble, al punto que Tesnière ha podido caracterizar la palabra «él mismo» en este género de empleo como un «equivalente estructural del verbo» ${ }^{29}$. Entendiendo por esto que el verbo es desde ahora, el verbo «convertirse-en-sí-mismo» o el verbo «ser-sí-mismo», y que «sí-mismo» no apela más a la cuestión «¿Quién?» en el sentido de una identificación. Descombes habla aquí de un «¿Quién?» circunstancial, en oposición a un «¿Quién?» actancial y, así, de una cuestión que se plantea sobre la manera de efectuar una acción -o de llevar una existencia-y no sobre la persona que lleva a cabo esta acción (o lleva esta existencia).

Estos apuntes, de hecho, parecen justos, pero se puede dudar que ellos permitan poner en evidencia el carácter gramaticalmente mal construido de la noción de ipseidad. Todo lo que ellos permiten mostrar, parece, es que existe una tensión entre dos afirmaciones de Heidegger: aquella según la cual la ipseidad es un modo de ser y aquella según la cual la ipseidad corresponde a un sentido específico de la identidad distinto de su sentido «ontológico-formal», es decir, de la identidad numérica a través del tiempo. En realidad, lo que Descombes afirma concierne a la gramática del «sí-mismo» en la expresión «ser símismo» parece más bien confirmar lo que Heidegger afirmaría con inmensa claridad, a saber, que la Selbstheit no es ninguna otra cosa que «un modo de existir (eine Weise zu existieren)». La cuestión de la ipseidad toca a la manera en que la existencia es llevada, y no al problema de saber quién lleva esta existencia (problema de identificación). Es verdad que el filósofo

\footnotetext{
${ }^{28}$ Ibíd., p. 159.

${ }^{29}$ Citado por Descombes, op. cit., p. 163.
} 
quiere introducir aquí «una nueva manera de plantear la cuestión del sujeto (la cuestión “¿Quién?”) y una nueva manera de utilizar los pronombres personales para responder a esta nueva cuestión del sujeto» ${ }^{30}$-o más bien una manera de emplear los pronombres personales que incluso ya está presente en el lenguaje corriente en el empleo de expresiones tales como «¡Sé tú mismo!»o «Yo no soy yo mismo»- pero no es del todo cierto, como lo concluye Descombes, que Heidegger «no [haya] fijado la gramática de esta nueva cuestión», pues parece al contrario que él ha fijado, en la advertencia al lector, que su cuestión lleva hacia eine Weise zu sein y a la modalidad de la relación consigo que surge de ella.

En suma, incluso si pasa que Heidegger se expresa de un modo diferente, como es el caso particular en ciertos cursos, por ejemplo, en los Problèmes fondamentaux de la phénoménologie, preguntándose por ejemplo «¿cómo es dado el sí?»» ${ }^{31}$, no hace falta olvidar que esta manera de expresarse está ligada en lo esencial a las licencias pedagógicas que él se autoriza, y partir de tales formulaciones no puede conducir sino al desconocimiento de la originalidad verdadera de su óptica sobre estas cuestiones. El problema de la ipseidad no es ni la cuestión del yo ni aquella del sí en el sentido que nos ha sido familiar desde Descartes y que conoce incluso, estos últimos tiempos, una suerte de inflación verbal incontrolada en gran número de escritos filosóficos.

Pero la mayor dificultad salida de la noción heideggeriana de ipseidad proviene ciertamente del hecho que es difícil decir lo que religa entre ellas las diferentes características de la ipseidad que he enumerado más arriba. ¿Cómo comprender que la ipseidad sea a la vez una manera de ser, una forma específica de identidad que permita aportar una respuesta a la cuestión “¿Quién?” entendida en el sentido especial, y una forma de la verdad en su sentido «más originario»? No es fácil responder a esta cuestión desde un punto de vista estrictamente heideggeriano, pues Heidegger nunca ha precisado, según nuestro conocimiento, lo que él entendería por «identidad» en el sentido específico que él pretende dar a esta noción cuando ella se relaciona únicamente al Dasein, y es difícil, en estas condiciones, ir más allá de las

\footnotetext{
${ }^{30}$ Ibíd., p. 161.

${ }^{31}$ M. Heidegger, GA 24, p. 225; trad. franc., Problèmes fondamentaux, op. cit., p. 196.
} 
formulaciones que conservan con él algo provisorio y programático. Yo me propondría aquí otra finalidad: esbozar una manera de concebir la articulación entre estas diferentes características -y especialmente entre la afirmación según la cual la ipseidad es una manera de ser y esa después de la cual ella responde a la cuestión «¿Quién?»- diferente de aquella que se le puede formular sobre la base de una lectura interna de Sein und Zeit, y que no cae, creo, en el ámbito de las objeciones «gramaticales».

\section{La ipseidad: un intento de reformulación}

Descombes afirma, con justa razón, que el género de la cuestión «¿Quién?» al que responde la ipseidad no puede ser la cuestión «¿Quién?» «ordinaria», la cual apunta a identificar o a re-identificar a alguien. Hace falta concluir entonces que «no hay equivocidad de la palabra francesa que significa la identidad $\rangle^{32}$, pero que existe solamente una diferencia entre un empleo no reflexivo de «él mismo», como en la frase «el asesino de Laos es el mismo Edipo» (sobre entendiendo: pero Edipo lo ignora), y un empleo reflexivo, como en la frase «Edipo ha descubierto que él es el mismo asesino de Laos» (él es consciente, él se ha identificado a sí mismo como siendo este asesino). En el primer uso, «él mismo» es un pronombre reflexivo de estilo directo (es aquel que habla quien identifica al héroe como siendo el mismo que el asesino); en el segundo empleo, es un pronombre reflexivo de estilo indirecto (es de hecho el héroe que habla, y estas son sus palabras que son relacionadas). Esta diferencia no afecta al concepto de identidad en tanto que tal, sino únicamente al género de relación consigo que es puesto en juego en ambos casos ${ }^{33}$.

Sin embargo, la afirmación según la cual la cuestión «¿Quién?» lleva en realidad sobre un solo y único sentido de la identidad es sorprendente, y más sorprendente aún de parte de un autor que apela a Wittgenstein, es decir, que se pone atento a la variedad de las palabras y de sus usos. En efecto, la cuestión «¿Quién?» puede ser empleada de muchas maneras en

\footnotetext{
${ }^{32}$ Descombes, Le parler de soi, p. 177.

${ }^{33}$ Ibíd., p. 178-179.
} 
francés, y no es simplemente verdadero que ella apele siempre a una respuesta en términos de identificación de alguien. Examinemos las tres cuestiones siguientes:

(1) ¿Quién sería el asesino de Laos?

(2) ¿Quién es verdaderamente Edipo?

(3) ¿Quién es Edipo?

La cuestión (1) es la que se formula el investigador que quiere penetrar en el secreto de la muerte de Laos: ella quiere establecer una identidad en el sentido de una identidad numérica. En otros términos, ella viene a establecer que, entre una multiplicidad de individuos, es idéntico con el asesino de Laos, o mejor, aquel que, entre una multiplicidad, es este asesino. La situación es entonces la siguiente: estamos en presencia de una variedad de sospechosos y se trata, entre ellos, de designar al culpable, es decir, a aquel que es idéntico con el autor del crimen. Recordemos que la identidad numérica - una noción tan simple que es prácticamente imposible de definir- es generalmente caracterizada como siendo la relación que cada cosa mantiene con ella misma, y con ninguna otra, a lo largo de su existencia. Esta definición, como lo ha hecho notar Wittgenstein, es desafortunadamente circular: decir que la identidad es la relación que una cosa mantiene con ella misma y con ninguna otra sería decir que es la relación que una sola y misma cosa mantiene con ella misma (y no con lo que no le es idéntico); es, entonces, presuponer lo que faltaría definir. Como escribe Wittgenstein, «decir de dos cosas que ellas serían idénticas es un absurdo, y decir de una cosa que ella sería idéntica a sí misma, no es decir nada en absoluto» ${ }^{34}$. Independientemente de esta dificultad, el primer empleo de «¿Quién?» viene a interrogarse sobre la identidad de un quién, en lo que sucede está caracterizado en medio de una descripción definida («el asesino de Laos»), es decir, sobre la identidad numérica de esta persona: es el sentido en el que piensa Descombes.

${ }^{34}$ L. Wittgenstein, Tractatus logico-philosophicus, 5.5303. En español es confiable la siguiente edición: Tratado lógico-filosófico. Logisch-philosophische Abhandlung, edición crítica de TS 204, introducción y traducción de Jesús Padilla Gávez, Tirant lo Blanch, Valencia, 2016 [NdT]. 
O la significación de (2), ¿no tiene nada que ver con este primer empleo de «¿Quién?»? ¿En qué circunstancias puede ser formulada una cuestión tal? Por ejemplo, un profesor podría dirigirla a sus alumnos en ocasión de un curso sobre la tragedia de Sófocles. Lo que el maestro querría entonces obtener es una descripción pertinente del género de personaje que es Edipo y no una identificación de este personaje. Si un alumno respondiera a esta cuestión señalando con el dedo una representación de Edipo, por ejemplo, aquella que figura sobre su ejemplar de Edipo rey, su reacción no podría sino desencadenar una explosión de risas general, pues lo que es requerido no es cuál, entre una multiplicidad de personajes, es Edipo, sino qué género de personaje es Edipo. Si la primera cuestión apunta a establecer una identidad numérica -es una cuestión identificante-, la segunda llama a una descripción -es una cuestión caracterizante $^{35}$. O, para decirlo de otro modo, la primera se interroga sobre la identidad en el sentido de la relación que cada cosa mantiene con ella misma y con ninguna otra, mientras que la segunda se interroga sobre un conjunto de características que pertenecen al individuo mencionado y permiten definirlo.

En cuanto a (3), ella es indeterminada, y su significación podría variar en función del contexto. Si esta cuestión es puesta por un director de escena frente a un grupo de actores, ella apelaría la mayor parte del tiempo a una identificación: Edipo (aquel que juega este rol) se le ha ordenado levantar la mano o responder «yo (moi)» para hacerse conocer. Si ella figura sobre la cubierta de un libro, ella constituye con toda probabilidad una cuestión caracterizante: ella apela a un análisis literario del personaje de Edipo.

A veces se ha llamado a este segundo sentido de la identidad «identidad cualitativa». La identidad numérica es cuestión de todo o nada: o bien A es numéricamente idéntica a $\mathrm{B}$, o bien no lo es. Y ser numéricamente idéntico a B, para A, significa tener todas sus propiedades en común con B. Dos cosas numéricamente idénticas son también, por este mismo hecho,

\footnotetext{
${ }^{35}$ Marya Schechtman ha puesto atención sobre esta distinción entre lo que ella llama «the reidentification question» $\mathrm{y}$ «the caracterization question»: «The characterization question does not ask about "identity" understood as "the relation which every object bears to itself and to nothing else", but rather as "the set of characteristics that make a person who she is» (The Constitution of Selves, Ithaca and London, Cornell University Press, 1996, pp. 75-76).
} 
indiscernibles: es el principio de la indiscernibilidad de los idénticos (para no confundirlo con el principio leibniciano de la identidad de los indiscernibles, que es mucho más controversial). La identidad numérica, en otros términos, es una identidad integral. No sucede de la misma manera para la identidad cualitativa. Esta última admite grados. Dos cosas son cualitativamente idénticas si ellas comparten ciertas propiedades y ellas pueden entonces ser más o menos idénticas en este sentido, en función del número de propiedades compartidas: dos pura sangres árabes comparten más propiedades que dos caballos. Entre estas propiedades, ciertas pueden ser calificadas de cualquier forma como «definicionales», como aquellas que pueden figurar de manera pertinente en una definición ${ }^{36}$. La identidad cualitativa es entonces una semblanza bajo cierta relación, ella constituye un sentido más débil de la identidad que la identidad numérica. Es también la razón por la cual ella ha sido generalmente tenida por poco interesante e incluso por despreciable por los filósofos. Por ejemplo, todos los debates en torno de la identidad personal que se han desarrollado desde hace más de cuarenta años en la filosofía analítica (con autores como John Perry, Sydney Shoemacker o Derek Parfit) han girado exclusivamente en torno de la identidad numérica e ignorado la identidad cualitativa. Y la razón principal de ello es que hay una cosa que la identidad cualitativa no permite hacer: es justamente identificar a alguien. Yo puedo escribir un libro entero para caracterizar a Jean-Paul Sartre, para decir «que él era» en este sentido, pero para aquel que no ha identificado ya a Jean-Paul Sartre, no hay ninguna descripción, no importa si es muy amplia y completa, será suficiente para indicar con quién se relaciona esta descripción. Pues toda descripción puede, al menos en principio, aplicarse a muchos individuos. Y ella lo puede porque toda descripción está por definición constituida de predicados generales (Sartre era un intelectual, un hombre de izquierda, un filósofo, un amigo de Simone de Beauvoir, etcétera, pero él no era, por cierto, el único individuo que era filósofo u hombre de izquierda o amigo de Beauvoir). En suma, la identidad cualitativa nos

\footnotetext{
${ }^{36}$ No todas las propiedades de una cosa pueden jugar este rol, pues entran aquí en juego consideraciones de pertinencia: por ejemplo, una propiedad puramente momentánea no puede llevar a cumplimiento esta función, salvo casos excepcionales. Sobre este problema ver las anotaciones de Oliver Black, «Personal Identity, Numerical and Qualitative» en Persons: An interdisciplinary Approach, 25. Internationales Wittgenstein Symposium, C. Kanzian, J. Quitterer et E Runggaldier éd., Austrain Ludwig Wittgenstein Society, 2002, pp. 31-32.
} 
enseña únicamente el género de individuo que sería Sartre y solo aquel entre muchos individuos que sería Sartre.

O, si el lógico tiene sin duda razón de privilegiar la identidad numérica para su propósito (por ejemplo para elaborar una teoría de la referencia), no es del todo seguro que el filósofo tenga razón de seguirle el ejemplo. ¿Qué es lo que permite responder de la manera más pertinente, a fin de cuentas, a la cuestión de saber quién era Sartre? ¿Son las características susceptibles de constituir los criterios de identidad (las condiciones necesarias y suficientes de la identidad de esta persona), tales como el ADN o sus huellas digitales? ¿O son las características del tipo de aquellas que se podrían encontrar en una buena biografía: lo que ha hecho de su vida, lo que ha querido y detestado, lo que ha creído y lo que daría sentido a su vida? Puede ser que formular la cuestión en estos términos pareciera tendencioso o caricaturesco (pues se supone que una biografía es más rica que las huellas digitales), pero en realidad no se trata de una cuestión de «riqueza» o de completud.

Para comenzar a verlo, hace falta volver a poner otra característica llamativa de la cuestión «¿Quién?». Esta cuestión no es generalmente empleada de la misma manera en la primera y en la tercera persona del singular. Cuando yo pregunto «¿Quién es ella?» yo puedo, en función del contexto, o bien, querer que mi interlocutor identifique para mí a esta persona («es la esposa de Pierre Martin»), o bien solicitarle que me proporcione una descripción pertinente de la persona que yo he identificado de antemano («Tú verás, es una persona muy abierta y simpática, que ha viajado mucho y que es muy curiosa»). Pero cuando yo empleo esta misma cuestión en la primera persona, salvo un caso extremadamente excepcional (por ejemplo, una amnesia total), lo que yo busco no es solamente una identificación. Cuando yo me pregunto «¿Quién soy yo?», como Mointaigne lo hacía en sus Ensayos, no quiero, evidentemente, establecer cuál es mi propia identidad (la identidad del autor de los Ensayos es bien conocida por él pues él firma su obra), sino solamente saber qué género de individuo soy. La respuesta a la cuestión de saber quién soy toma entonces la forma de una descripción de mi identidad cualitativa, y más precisamente de propiedades susceptibles de definirme, de responder a la cuestión «¿Quién soy yo?» entendido en un sentido especial -en un sentido 
que difiere del uso estándar de «¿Quién es él?» en la tercera persona cuando esta cuestión es empleada para identificar a alguien.

Pero hace falta ir más lejos. ¿Cómo comprender, en efecto, que la cuestión caracterizante permite captar mejor quién es alguien que la cuestión identificante? ¿Qué es lo que permite afirmar que yo soy mejor definido por lo que creo, emprendo y siento en el transcurso de las peripecias de mi vida sino por los elementos de información objetiva tales como mi nombre, mi ADN o mis huellas digitales? El hecho que yo mantengo una relación especial en el primer género de cosas, y no en el segundo. Cuando yo me defino (o cuando se me define), por mis convicciones, mis proyectos e intenciones, mis inclinaciones y mis desapegos, etcétera, se me define también al mismo tiempo por las características en relación con las cuales ejerzo una forma de responsabilidad. Responsabilidad, por cierto, diferente en estos distintos casos: a) las creencias no son solamente algo que yo tengo, sino aún algo que yo debo asumir para que ellas sean realmente mis creencias, y asumir una creencia es hacerse responsable de eso que se afirma, es decir, asumir la carga de dar justificaciones si alguien (incluido yo mismo) me las pide; b) los proyectos, las intenciones, son algo de lo que yo soy responsable, así como de las acciones que pongo en obra para realizar estas intenciones o proyectos: hay intenciones censurables e incluso criminales; 3) mis reacciones afectivas y emotivas revelan un régimen totalmente distinto de responsabilidad: ellas están surgiendo espontáneamente en mí sin que yo sea su causa o su autor, pero ellas son al menos expresivas de mí mismo, lo que implica que es posible imputármelas al menos en ciertas circunstancias: la indiferencia mostrada frente a una tragedia o una injusticia, el placer sádico experimentado frente al sufrimiento del otro son condenables al mismo tiempo que las acciones o las omisiones, pues ellas traicionan justamente quién soy. Así, se puede sostener que entre las múltiples características que pertenecen a mi identidad cualitativa, algunas se liberan con una fuerza particular, porque están ahí las características en vista de las cuales ejerzo una forma de responsabilidad, e incluso a veces las características que no pueden sucederme (y definirme) solo si yo ejerzo a su consideración una forma de responsabilidad. Por ejemplo, existe una diferencia importante entre las creencias que tenemos sin haberlas jamás examinado e incluso, sin saber que las tenemos, porque ellas constituyen los elementos de nuestra «imagen del mundo», como diría 
Wittgenstein, y las creencias que nosotros asumimos expresamente, es decir, creencias tales que, al asumirlas, nos hacemos justamente responsables de lo que afirmamos, nos sometemos a la crítica y nos comprometemos a proporcionar las justificaciones necesarias. La aceptación de una creencia en una espacio social equivale a un compromiso que nosotros tomamos, y así, al ejercicio de una responsabilidad en relación con la creencia asumida. Y esto vale también para una declaración de intención o, en ciertos casos, para la comunicación de un sentimiento, por ejemplo, de una declaración de amor.

Dejando de lado la cuestión de las diferentes formas que pueden revestir esta responsabilidad, intentaré precisar qué rol juega ella en la elucidación de la cuestión que nos ocupa. La ipseidad, decía anteriormente, puede ser definida a la vez como una manera de ser, una modalidad de relación consigo y un sentido posible de la identidad. Yo intentaré ahora dar a esta afirmación contornos más precisos. La ipseidad indica una manera de ser en este sentido que ella consiste en el ejercicio de una cierta forma de responsabilidad en relación con nuestro «ser», como diría Heidegger, o aún en relación con ciertos elementos de nuestra identidad cualitativa, aquellos que nos incumben, y así aquellos en relación con los cuales estamos justificados a ejercer esta responsabilidad: yo no puedo ejercer una responsabilidad en relación al hecho de haber nacido tal día o tener este color de piel; pero yo puedo ejercer una responsabilidad en relación al hecho de creer esto o aquello, de tener esta o aquella ambición o de reaccionar afectivamente de una manera determinada a una situación (o menos sentirme culpable de tener ciertos sentimientos y emociones). La ipseidad es entonces un género de actitud, una actitud de responsabilidad, y esta actitud se ejerce no en relación con nuestro ser, o nuestra identidad indistintamente, sino en relación con una cierta parte de nuestra identidad: aquella que se puede caracterizar como nuestra «identidad cualitativa en primera persona», es decir, esta parte de nuestra identidad que, contrariamente a los elementos de nuestra identidad cualitativa que son esos que han hecho abstracción del género de relación que nosotros mantenemos frente a ellos (como el color de nuestra piel o nuestra fecha de nacimiento), esto es, contrariamente a lo que se podría llamar nuestra «identidad cualitativa en tercera persona», no constituyen una parte de nuestra identidad sino en tanto que 
ejercemos en relación a una responsabilidad inalienable. Por ejemplo, una creencia no puede ser un elemento de nuestra identidad sino en la medida en la que asumimos frente a los otros $\mathrm{y}$, de este hecho mismo, asumimos a la vez la tarea de ofrecer justificaciones y todas las consecuencias prácticas que surgen de allí. A diferencia de nuestra identidad en tercera persona, que es de lo que ella ha hecho abstracción de nuestra actitud a su consideración, nuestra identidad en primera persona depende estrechamente de la relación que mantenemos con ella, es decir, de las modalidades de responsabilidad que ejercemos en relación con nuestro «ser» (como diría Heidegger), o aún más en relación con nuestras creencias, intenciones, proyectos, acciones, reacciones afectivas, etcétera, y así también con nuestra capacidad de modificar este ser y en «hacernos» aquello que somos (por ejemplo, en revisar nuestras creencias o en transformar nuestras reacciones afectivas) -y esta es la razón por la cual esta identidad en primera persona nos define de manera mucho más «íntima» que la primera.

La ipseidad es entonces a la vez un modo de existencia (una existencia sobre el modo de la responsabilidad frente y por los otros), una modalidad de la relación consigo (pues para poder asumir una creencia, es necesario ser consciente de tener esta creencia, es necesario entonces ser en la medida de serme atribuida y, por lo tanto, de tenerla o de reconocerla), y si no una forma de identidad, al menos un aspecto de nuestra identidad (cualitativa), este aspecto de nuestra identidad en relación a la cual podemos ejercer una forma de responsabilidad (diferente en lo que concierne a las creencias o a las emociones) en la medida en que nosotros mismos contribuimos a «formar» o a dar consistencia a esta identidad. Si no podemos, en efecto, darnos creencias a voluntad, podemos al menos contribuir a someter nuestras creencias a un examen racional; si no nos decidimos soberana y discrecionalmente por nuestras emociones y reacciones afectivas, podemos al menos intentar reprimir o hacer callar ciertos sentimientos en nosotros y, en este sentido, ellos nos son, al menos en parte, imputables, dando a veces lugar a sentimientos reflexivos complejos como la vergüenza de experimentar los sentimientos en cuestión. La ipseidad, en el sentido que nosotros queremos dar a este término, designa en consecuencia la actitud que consiste en ejercer una forma de responsabilidad y de responder frente a los demás de estos aspectos de nuestra identidad 
cualitativa en primera persona que nos definen de la manera más íntima (deseos, creencias, intenciones, sentimientos pero también acciones) porque nosotros somos susceptibles de ejercer a nuestra consideración una forma de responsabilidad singular y porque esta responsabilidad singular es justamente lo que hace de ellos los aspectos de nuestra identidad en el sentido aquí pertinente. O más bien, la ipseidad no es tanto esta actitud como la capacidad (adquirida a través de la educación) de adoptar una actitud en relación con los aspectos centrales de nuestra identidad (una actitud que no es la nuestra, por ejemplo, cuando dormimos, y puede ser cuando no pensamos en nada o actuamos mecánicamente). Definida con más precisión, la ipseidad, en un sentido que me parece tanto semejante como diferente del que ese término posee en Sein und Zeit, designa mi capacidad de hacerme responsable y garante frente al otro de esta parte de mi identidad (cualitativa) en primera persona, por la cual el hecho de hacerme garante es la condición necesaria para que ella sea mi identidad.

De aquí surgen tres consecuencias y una dificultad.

En principio, la dificultad: la cuestión «¿Quién soy yo?» en la primera persona del singular y en el presente del indicativo no es solamente diferente de la cuestión «¿Quién es él o ella?» en la tercera persona en eso que ella no pone (salvo en casos excepcionales) sobre mi identidad numérica, sino únicamente sobre mi identidad cualitativa (y con mayor precisión sobre esta parte de mi identidad cualitativa que ha sido llamada arriba «en primera persona»). Las dos cuestiones difieren también en aquello que la cuestión «¿Quién soy yo?» oculta en cierta ambigüedad que no existe para la cuestión «¿Quién es él/ella?». Aquel que se interroga así quiere, en efecto, describir que ha sido él hasta el presente, y entonces se describe de la manera en la que él describirá a cualquier otra persona, ¿formulará un juicio sobre su propia conducta pasada, sobre sus disposiciones afectivas tal como ellas han sido hasta el presente, sobre sus ambiciones tal como él se las formularía hasta aquí, etcétera? En este caso, él apunta a un conocimiento de él mismo que valida fundamentalmente la misma forma que el conocimiento del otro - pues, como escribe Schlegel, «nadie se conocería siempre que no 
fuese sino él mismo y al mismo tiempo otro» ${ }^{37}$. O bien, aquel que se interroga así quiere interrogarse sobre aquello a lo que él aspira a ser, ¿él quiere tomar posición y comprometerse en relación a tener una actitud, llevar a cabo una especie de promesa, llevando sobre aquello que será, enviada a otro o a él mismo (si se supone que la idea de una promesa consigo tenga sentido)? En cuyo caso, su ejercicio de definición describe menos una realidad pasada o presente que una posibilidad o una exigencia. Él se presenta a los otros y a sí mismo como siendo esencialmente un «poder-ser», para retomar la terminología de Heidegger. Me parece importante señalar, sin embargo, que esta ambigüedad constitutiva de la cuestión «¿Quién soy yo?» no sabría ser resuelta en favor de uno de sus dos sentidos exclusivamente. No es verdad que nuestra identidad «real» sea aquella que nosotros «hacemos», y que la otra, aquella que está ya hecha, aquella que pertenece a nuestro pasado, y es para nosotros un dato inmutable, sería únicamente aparente. Es la ilusión en la cual cae una concepción como la de Sartre (y, en una menor medida, de sus herederos analíticos contemporáneos) cuando ella pretende devolver toda identidad dada (es decir, dada independientemente de mi libertad presente), y así de toda identidad pasada tal como ella se nos presenta como «de hecho», como terminada e inmutable, como puro objeto de conocimiento, al parecer de una identidad fáctica, de la cual la invocación para aquel que la posee revelaría pura y simplemente la mala fe. Incluso si ejerzo una forma de responsabilidad singular en relación con mi propia identidad, mi ser no se reduce solamente a eso que yo hago, contrariamente a la fórmula de Sartre, y por tanto, yo no soy únicamente «ese que me hago ser». Así, me ocupo de la consideración de mí mismo y de mi propia identidad, o más bien de ese aspecto de mi identidad que yo he llamado «identidad en primera persona», una posición excepcional, pues tengo una responsabilidad singular en relación a esta identidad. Pero esta responsabilidad no es una responsabilidad total, y aún menos «infinita»: esta identidad yo no la creo, yo no la «constituyo», yo no la «elijo» en absoluto; yo tengo una responsabilidad, pero limitada, en su consideración.

\footnotetext{
${ }^{37}$ Schegel, «Sur Lessing», cité par Hugo von Hofmannsthal, Le livre des amis, in Euvres en prose, Paris, Le livre de Poche, 2010, p. 796.
} 
Llegamos a las consecuencias de esta caracterización de la ipseidad. Ella permite darle derecho a otras tres características mencionadas por Heidegger, pero de una manera diferente a las que él indica.

1) Ante todo, ella permite comprender el lazo necesario que existe entre ipseidad y verdad. Heidegger, como lo ha observado Tugendhat, se ha equivocado sin duda al conferir al concepto de verdad una extensión tan considerable, hasta hacerle designar la apertura misma del Dasein al ente en su conjunto. Por ello, él ha despojado la verdad de ciertas de sus características esenciales. Sin embargo, no se sigue que no sea legítimo entrever la posibilidad de formas de verdad «antepredicativas» y no-proposicionales que concernirían a nuestra manera de ser, de conducirnos y de presentarnos a los otros. En realidad, en la medida donde la ipseidad designa mi capacidad de adoptar cara a cara de mi propia identidad en primera persona una actitud de responsabilidad y de portarme así garante de que yo soy frente a los otros, ella no es posible sino correlacionada a una forma de veracidad, excluyendo por ello también todas las formas de negación de responsabilidad en las cuales yo me descarto de mi responsabilidad sobre los otros (eso que se puede llamar legítimamente «mala fe») como las formas del engaño deliberado al otro, de la manipulación y la disimulación extrema (yo entiendo por esto una disimulación que va más allá de las precauciones para no lastimar al otro y de las formas elementales de la civilidad). Como dice Heidegger, la ipseidad es una forma de autenticidad y de «verdad de la existencia» en oposición a las formas de falsedad existencial por la fuga frente a mi responsabilidad; o aún, si se quiere adoptar el vocabulario de Ricoeur, ella va a la par con la «confirmación», es decir, con un testimonio fiable y verdadero relativo a mi ser. Esta «verdad» no significa «la apertura» sin más del Dasein, sino la existencia de aquel en conformidad con lo que él es o le hace mostrarse a él mismo bajo su propio rostro.

2) En tanto que capacidad, la ipseidad es adquirida en medio de procesos de socialización y de educación. Nadie, en efecto, es «él mismo» en este sentido en su nacimiento, y si él adquiere esta capacidad de responder por él mismo, es por el intermediario de otros que lo han adquirido antes de él. Un pensamiento de la ipseidad rompe así el horizonte monológico 
(e incluso potencialmente solipsista) en el cual se encierran inexorablemente los pensamientos del «yo (moi)» o del «sí (soi)» desde Descartes. La capacidad de ser yo-mismo en el sentido de la ipseidad no existe, en efecto, sino delante del otro y en el cara-a-cara con él, y ella no ha sido adquirida por sí mismo sino por el intermediario de los otros: ella es entonces social de principio a fin. O, aún para decirlo de otro modo: nadie puede ser «élmismo», en el sentido de la ipseidad, por sí solo, y tampoco nadie puede ser el único en ser «él-mismo» en este sentido, ya que la adquisición misma de esta capacidad toma por modelo una capacidad análoga con los otros y se ejerce ella misma en relación con los otros. Con un pensamiento de la ipseidad, hemos superado definitivamente el espectro del solipsismo.

3) Finalmente, la ipseidad pone en juego una forma de «constancia» o una permanencia que no es la de un sustrato o de un sujeto. Queda por comprender cuál es su naturaleza. En principio, conviene precisar que aquel que posee la ipseidad (o existe sobre el modo de la ipseidad) posee por otro lado una permanencia de este tipo, él puede ser identificado y reidentificado como lo mismo, pues de otro modo, esta ipseidad no sería la de alguien y no podría tampoco decir de quién es ella, la ipseidad. Pero la ipseidad, si supone la identidad en sí a través del tiempo de aquel del que ella es la ipseidad, no posee por tanto el mismo género de permanencia o de duración que aquel del individuo en cuestión. Si, en efecto, admitimos que la ipseidad es la capacidad de ejercer una responsabilidad inalienable en relación consigo misma frente a los otros y a no defraudarlos ni a defraudarse, y entonces, la capacidad de existir en una forma de verdad en su consideración, queda que esta capacidad, como toda capacidad, no tiene solamente el mismo género de permanencia que un estado revestido, en el vocabulario de Wittgenstein, de «duración auténtica (echte Dauer)». La ipseidad no tiene ni la permanencia de una cosa, ni aquella de un estado, sino el género de permanencia que pertenece a una capacidad. Mientras que, para un estado, hay un sentido para preguntarse cuándo ha comenzado y terminado, si él estaba contenido o discontinuo, si admitiría variaciones, por ejemplo, las variaciones de intensidad, este género de cuestión no tiene sentido a propósito de una capacidad. En efecto, una capacidad puede ser adquirida en un momento dado, y ella puede permanecer presente en mí mismo si yo no la ejerzo; incluso queda, al menos, que si, en cierto sentido, ella puede ser llamada «persistir», no es cierto en 
el sentido en el que yo estaría en algún estado durante todo el tiempo en el que la poseo. Como escribe Wittgenstein, «lo que distingue a todos los estados de conciencia de las disposiciones, consiste, me parece, en que no es necesario recurrir a los controles intermitentes para asegurarse que ellos duran todavía ${ }^{38}$. Hay entonces un sentido al hablar de esta actitud de ser yo-mismo como de una actitud adquirida en medio de la educación y de la socialización, pero esta no nos obliga de ninguna manera a pensar esta actitud como «manteniéndose» en el curso del tiempo a la manera de una cosa o de un estado.

Sin embargo, no nos equivoquemos: si la ipseidad consiste en ejercer una responsabilidad frente al otro en relación con lo que soy; aquello con lo que me compromete una responsabilidad tal no permanecerá ni idéntico, ni constante, ni simplemente va a atenerse a mi identidad pasada y presente como lo haría la palabra dada; ella me compromete tanto en función de la variabilidad y de la novedad de las situaciones, como para romper con las convicciones, con las creencias, e incluso, con los compromisos que la aparición de esta situación nueva ha hecho ya inadaptados y caducos. Ella no me compromete únicamente para poder mantener mi palabra, sino también, en función de los parámetros múltiples de la situación que sería vano pretender enumerar, para cambiar y abandonar aquellos aspectos de esta identidad que han devenido superfluos, insostenibles o que han sido superados.

Claude Romano

\footnotetext{
${ }^{38}$ Wittgenstein, Remarques sur la philosophie de la psychologie, éd. Bilingüe, trad. de G. Granel, Mauvezin, TER, 1994, II, § 57.
} 


\section{Bibliografia:}

Black, O. (2002), «Personal Identity, Numerical and Qualitative» en Persons: An interdisciplinary Approach, 25. Internationales Wittgenstein Symposium, C. Kanzian, J. Quitterer et E Runggaldier éd., Austrain Ludwig Wittgenstein Society.

Descombes, V., (2014) Le parler de soi, Paris, Gallimard.

Ernout, A. et François Thomas, (2002), Syntaxe latine, Paris, Klincksieck.

Granel, G., (1995) «Ipse Dasein?» en Études, París, Éditions Galilée.

Heidegger, M., (1925) Prolegomena zur Geschichte des Zeitbegriffs, GA 20, ed. P. Jaeger, 1979, $2^{\text {a }}$. Ed. 1988, $3^{\text {a }}$. Ed. 1994.

- - - (2001), Sein und Zeit, Deutschland, Max Niemeyer Verlag Tübingen.

- - - (1997), Die Grundprobleme der Phänomenologie, GA 24, ed. F.-W. von Herrmann, 1975, 2a . Ed. 1989, 3. Ed. 1997.

Hoffmansthal, H., (2010), Euvres en prose, Paris, Le livre de Poche.

Schechtman, M., (1996) The Constitution of Selves, Ithaca and London, Cornell University Press.

Wittgenstein, L., (1994), Remarques sur la philosophie de la psychologie, éd. Bilingüe, trad. de G. Granel, Mauvezin, TER.

- - (2016), Tratado lógico-filosófico. Logisch-philosophische Abhandlung, edición crítica de TS 204, introducción y traducción de Jesús Padilla Gávez, Tirant lo Blanch, Valencia, 2016. 